\title{
Phytochemical screening, antifungal and antioxidant activities of three medicinal plants from Algerian steppe and Sahara (preliminary screening studies)
}

\author{
Mohamed Amine Gacem ${ }^{1,2} \cdot$ Alia Telli $^{1} \cdot$ Hiba Gacem $^{3} \cdot$ Aminata Ould-El-Hadj-Khelil $^{1}$
}

Received: 4 October 2019 / Accepted: 26 November 2019 / Published online: 28 November 2019

(c) Springer Nature Switzerland AG 2019

\begin{abstract}
The contamination of foodstuffs by fungi and their mycotoxins, emergence of resistance to fungicides and unwanted side effects of pesticides on human and animal health currently present a challenge for researchers to create and innovate new and better solutions to fight against mycotoxigenic fungi with less harmful effects on the consumer and the environment. In the context of the valorization of natural products, this study aimed, first, to determine the phytochemical composition of methanolic and aqueous extracts of Pistacia lentiscus, Artemisia herba-alba and Citrullus colocynthis and, second, to evaluate the antifungal potential and antioxidant capacity of these extracts. The extraction of crude active compounds from selected plant species was carried out by methanolic and aqueous maceration. Antifungal activity against five fungal strains (Aspergillus flavus, Aspergillus parasiticus, Fusarium graminirium, Aspergillus ochraceus and Penicillium expansum) was evaluated by the dilution method in solid medium. Analysis of antioxidant activity was carried out by three tests, namely, the inhibition of $\mathrm{ABTS}^{++}$radical cation, trapping of DPPH' radical and reduction of Fe ${ }^{2+}$ (FRAP). The results show that the crude extracts were rich in bioactive compounds and that the crude methanolic and aqueous extracts of $A$. herba-alba were the most active against the tested fungal strains and had a percentage of inhibition exceeding $8 \%$. Regarding antioxidant activity, all the extracts exhibited remarkable antioxidant potential in the tests used. The methanolic extract of $A$. herba-alba had the highest iron-reducing capacity. The results show that the studied medicinal plants could be a good alternative for protecting foodstuffs against toxigenic fungi.
\end{abstract}

Keywords Pistacia lentiscus · Artemisia herba-alba · Citrullus colocynthis · Antifungal activity · Antioxidant activity

\section{Introduction}

Mycotoxins are secondary metabolites produced by six fungal genera, namely, Aspergillus, Alternaria, Claviceps, Fusarium, Penicillium and Stachybotrys. These metabolites commonly occur in foodstuffs and cause diseases in consumers [1]. Depending on the administered dose, the toxicity can spread to all vital human and animal organs and cause oxidative stress [2], which leads to nephrotoxicity
[3], genotoxicity [4], neurotoxicity [5], hepatotoxicity [6], immunotoxicity [7], gastrointestinal toxicity [8], and cardiotoxicity [9]. Long periods of exposure to mycotoxins contribute to cancer development [10].

To limit the presence of mycotoxinogenic fungi in food and the mycotoxicoses caused by the consumption of contaminated foods, a control policy has been applied in recent years that is based on prevention of contamination, on decontamination and on protection against the

$\triangle$ Mohamed Amine Gacem, biologieamine@yahoo.fr | 'Laboratory of Ecosystems Protection in Arid and Semi-Arid Area, University of Kasdi Merbah, 30000 Ouargla, Algeria. ${ }^{2}$ Department of Biology, Faculty of Science, University of Amar Tlidji, 03000 Laghouat,

Algeria. ${ }^{3}$ Epidemiology Service and Preventive Medicine, Hassani Abdelkader University Hospital Center, Faculty of Medicine, University of Djillali Liabes, 22000 Sidi-Bel-Abbès, Algeria. 
toxicities of mycotoxins by the application of several physical, chemical and biological techniques [11]. However, it is very difficult to destroy mycotoxins by physical techniques without altering food quality [12]; moreover, the use of chemical processes also has undesirable effects because chemical compounds participate in the generation of free radicals and, therefore, the induction of oxidative stress $[13,14]$. At the same time, the massive use of antibiotics in agriculture is a cause for alarm with respect to public health [15] due to antibiotic-induced oxidative stress and to the emergence of multiresistant strains [16-18]. To resolve this problem, several studies investigated the use of essential oils and medicinal plant extracts as a safe alternative in the field of phytoprotection, which is the fight against toxigenic moulds and mycotoxicoses $[19,20]$. Reddy et al. [21] showed that aqueous extracts of some plant species (Allium cepa, Allium sativum, Curcuma longa, Ocimum sanctum, Syzigium aromaticum, etc.) are rich in bioactive chemical compounds that inhibit the biosynthesis of aflatoxin. A study conducted by Elsherbiny et al. [22] demonstrated that the essential oils of Ocimum basilicum completely inhibited the growth of several species of Bipolaris and the germination of Bipolaris hawaiensis spores. However, the use of medicinal plants from arid and semiarid regions of Algeria as an alternative in the process of food product decontamination has not been extensively studied.

Many medicinal plant species from steppe and desert regions are known for their therapeutic virtues and are traditionally used by the local populations to treat various diseases. These steppe and Saharan species, which include Pistacia lentiscus (Anacardiaceae), Artemisia herba-alba (Asteraceae) and Citrullus colocynthis (Cucurbitaceae) have remarkable antidiabetic, antibacterial, anti-tumoural, antiinflammatory and anticancer properties [23-29]. Therefore, the objective of this study was to determine the phytochemical composition of the aqueous and methanolic extracts of $P$. lentiscus, A. herba-alba and $C$. colocynthis and to evaluate their antifungal and antioxidant potency.

\section{Materials and methods}

\subsection{Harvest and preparation of medicinal plants}

The plants that are the focus of this study are known for their therapeutic virtues in traditional Algerian medicine [30]. The leaves of $P$. lentiscus were harvested in the region of Tifrit ( $34^{\circ} 56^{\prime} 04.2^{\prime \prime} \mathrm{N}, 0^{\circ} 22^{\prime} 48.9^{\prime \prime} \mathrm{E}$ ) in December 2017. For the second species, the aerial part of $A$. heba-alba was harvested in the region of Maamoura $\left(34^{\circ}\right.$ $42^{\prime}$ 06.7" N, $0^{\circ} 28^{\prime}$ 58.7" E) in March 2017. Regarding $C$. colocynthis species, fruit were harvested in December
2016 from the desert region of Oued N'sa $\left(32^{\circ} 48^{\prime} 13.7^{\prime \prime}\right.$ $\left.\mathrm{N}, 3^{\circ} 48^{\prime} 13.6^{\prime \prime} \mathrm{E}\right)$. The geographical location of harvesting sites is illustrated in Fig. 1. The botanical identification of plant species was carried out by botanists from the plant biology laboratory of Saida University (Algeria). To achieve the targeted aim of the study, the plant parts used were the leaves of $P$. lentiscus and A. heba-alba and the seeds of $C$. colocynthis.

\subsection{Extraction and phytochemical screening}

P. lentiscus and A. heba-alba leaves and C. colocynthis seeds were first washed with distilled water and disinfected for 30 min by immersion in a $2 \%$ solution of sodium hypochlorite. The plant material was then rinsed with distilled water to remove residual hypochlorite. After open air drying away from light, the plant material was crushed roughly using a grinder (Moulinex Grinder AR110027) [31], and the powders obtained from each species were divided into two quantities for subsequent methanolic and aqueous extractions.

A quantity of $20 \mathrm{~g}$ of each plant powder was mixed with $100 \mathrm{ml}$ of solvent (methanol [Sigma-Aldrich-Germany] or water) for $3 \mathrm{~h}$ under continuous stirring ( $200 \mathrm{rpm}$ ) in MS Orbital Shaker at room temperature. The mixture was then filtered using Whatman filter paper (No 4). This operation was repeated four times with renewal of the solvent to deplete the marc and increase the yield. At the end of the extraction, the fractions of each extraction were collected, and the methanolic extracts were evaporated to dryness using a rotavapor (Heidolph-Germany) [32], while the aqueous extracts were lyophilized. Extract powders were kept in dark bottles at $4{ }^{\circ} \mathrm{C}$ until use. Figure 2 shows the methanolic and aqueous extraction steps followed in this study. The qualitative detection of alkaloids, saponins, flavonoids, and tannins was carried out following the protocols described in the study done by Al-Daihan et al. [33].

\subsubsection{Test for alkaloids}

Each dry extract powder $(100 \mathrm{mg}$ ) was dissolved in $5 \mathrm{ml}$ of methanol and then filtered. $5 \mathrm{ml}$ of hydrochloric acid (1\%) was mixed with $2 \mathrm{ml}$ of the filtrate, and then $1 \mathrm{ml}$ of the mixture was taken separately in two test tubes. Few drops of Dragendorff's reagent (potassium iodide-bismuth nitrate) were added in the tube and appearance of orangered precipitate was taken as positive. Few drops of Mayer's reagent (composed of mercuric chloride and potassium iodide dissolved in distilled water) were added to the second tube and appearance of buff-colored precipitate designates the existence of alkaloids. 


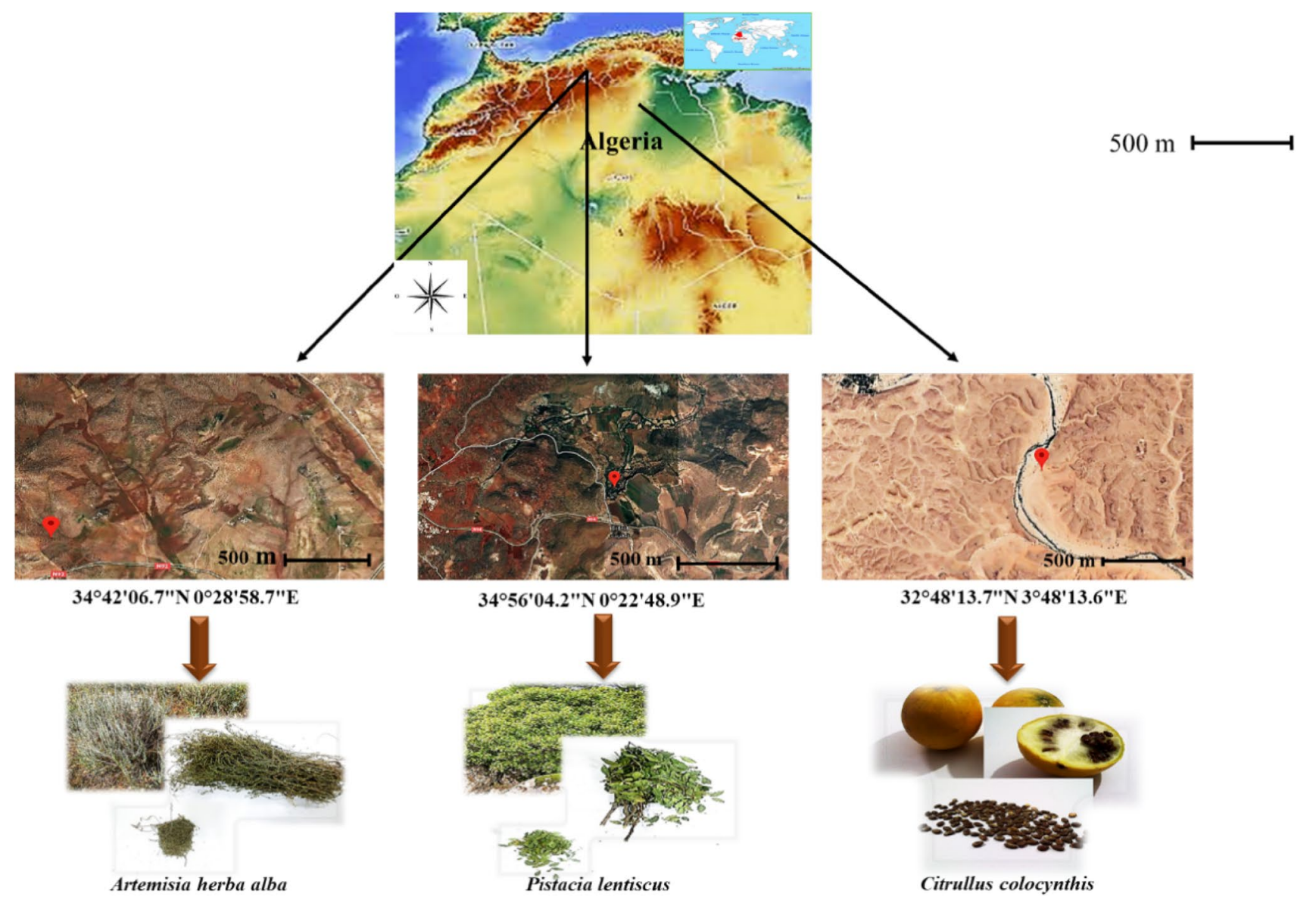

Fig. 1 Geographic location of medicinal plant harvesting stations

\subsubsection{Test for saponins}

$10 \mathrm{ml}$ of distilled water was mixed with $1 \mathrm{~g}$ of powdered dry extract and then boiled and filtered. The filtrate was mixed again with $3 \mathrm{ml}$ of distilled water and shaken for $5 \mathrm{~min}$. Appearance of foam after shaking designates the existence of saponins.

\subsubsection{Shinoda's test for flavonoids}

$500 \mathrm{mg}$ of powdered dry extract was added to $5 \mathrm{ml}$ of ethanol, the mixture is slightly heated and then filtered. The filtrate was added to some pieces of magnesium chips, a few drops of concentrated $\mathrm{HCl}$ was then added to the mixture. Occurrence of a pink, orange, or red to purple coloration designates the existence of flavonoids.

\subsubsection{Test for tannins}

$500 \mathrm{mg}$ of powdered dry extract was added to $10 \mathrm{ml}$ of distilled water, the mixture is then filtered and few drops of $1 \%$ ferric chloride solution are added to the filtrate.
Occurrence of a blue-black, green or blue-green precipitate designates the existence of tannins.

\subsection{Assessment of antifungal activity}

Five fungal strains were selected to evaluate the antifungal activity of the different extracts: $A$. flavus CECT 20802 (producing aflatoxin $\mathrm{B}_{1}\left(\mathrm{AFB}_{1}\right), \mathrm{AFB}_{2}, \mathrm{AFM}_{1}$ and $\left.\mathrm{AFM}_{2}\right), A$. parasiticus CBS 100926, F. graminirium CECT 2150, A. ochraceus NRRL 3174 (producing ochratoxin) and P. expansum CECT 2278 (producing patulin and citrinin). The purity of the strains was verified by the microculture chamber (slide culture) with some modifications [34], this technique takes place in a few steps; (1) using a sterile blade cut out the PDA medium $(10 \times 10 \mathrm{~mm})$ to fit under a coverslip, (2) deposit the PDA block on a sterile blade, (3) inoculate the four sides of the PDA block with spores of the strain to be grown, (4) cover the PDA block with a flamed coverslip, (5) incubate the plate at $30^{\circ} \mathrm{C}$ during 15 days, (6) transfer the coverslip on a new clean glass slide containing a small drop of lactophenol blue solution, (7) examine the slides under optical microscope. 
Fig. 2 Methanolic and aqueous extraction protocol carried out on the plants

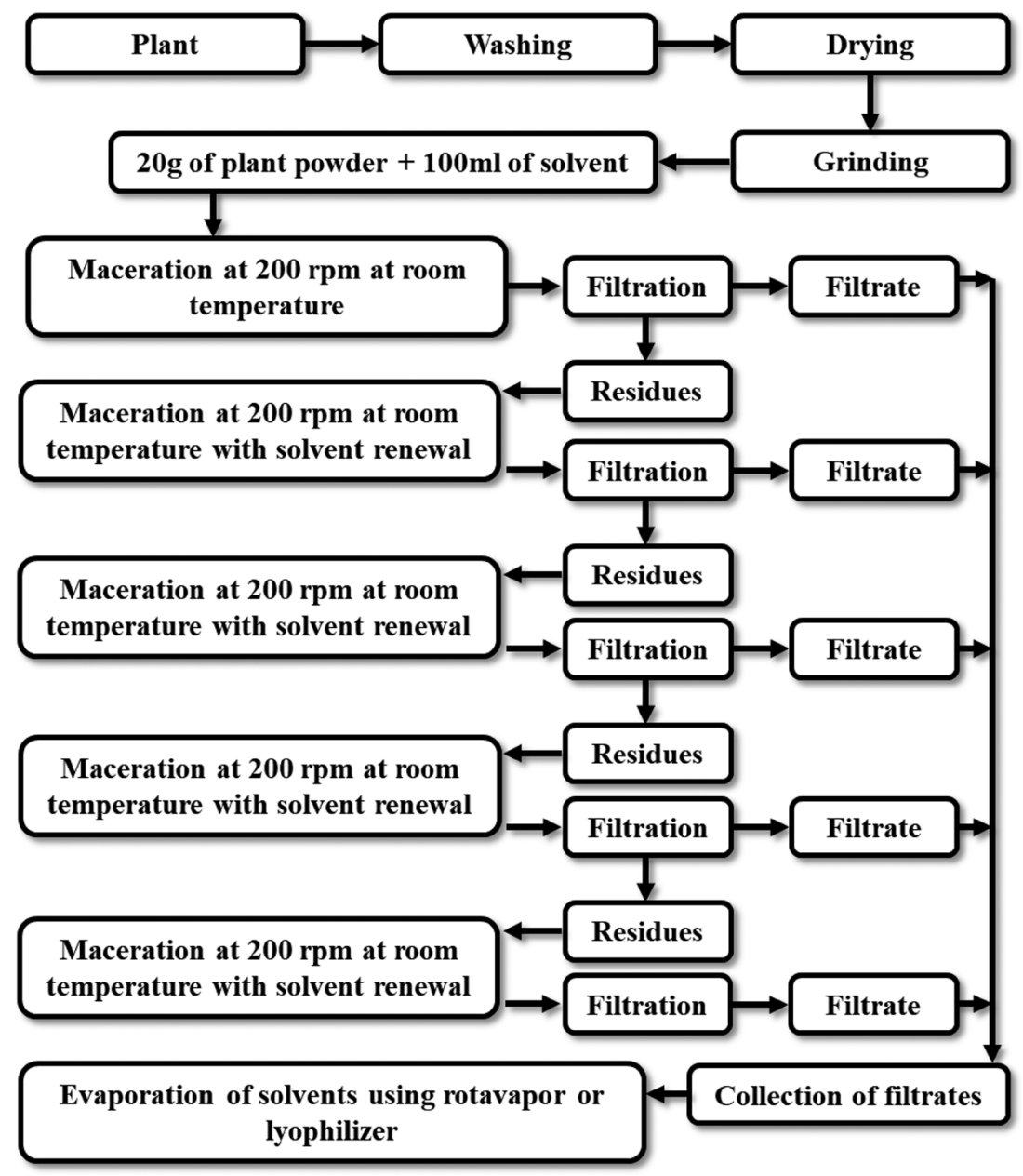

Antifungal activity was measured by the protocol described by Magnusson and Schnürer [35] with some modifications. As described by Espinel-Ingroff and Cantón [36], spore solutions were prepared from seven-day-old cultures of each strain, and their concentrations were adjusted with a spectrophotometer (Jenway 6315- United Kingdom) set to $530 \mathrm{~nm}$ to obtain suspensions of $5 \times 10^{6}$ viable conidia or sporangiospores per milliliter. A volume of $100 \mu$ of each suspension (diluted to approximately $5 \times 10^{4}$ CFU.ml ${ }^{-1}$ ) was used to flood-inoculate PDA medium that had been solidified in Petri dishes. A dilution series $\left(25,50,75\right.$ and $\left.100 \mathrm{mg} \mathrm{ml}^{-1}\right)$ was prepared for each plant extract, and $40 \mu \mathrm{l}$ of extract dilution was injected into the wells of inoculated PDA medium. The dishes were incubated for 5 days at $27 \pm 2{ }^{\circ} \mathrm{C}$. Antifungal activity was calculated by dividing the surface area of growth inhibition due to the extract by the total surface area of the petri dish and multiplying by $100 \%$ [35]. The results were categorized as follows:

- If the inhibition was between 0.1 and 3\%, the antifungal activity was considered low.
- If the inhibition was between 3 and $8 \%$, the antifungal activity was considered average.

- If the inhibition was greater than $8 \%$, the antifungal activity was considered to be high.

\subsection{Determination of antioxidant activity}

\subsubsection{ABTS radical scavenging assay}

To measure the antioxidant capacity by monitoring inhibition of the $\mathrm{ABTS}^{++}$radical cation, the method described by Surveswaran et al. [37] was followed. The generation of $\mathrm{ABTS}^{\cdot+}$ radical cation was carried out by a chemical reaction between a solution of ABTS $(7 \mathrm{mM})$ and a solution of potassium persulfate $(2.45 \mathrm{mM})$ incubated for $16 \mathrm{~h}$ in the dark at room temperature. The resulting ABTS ${ }^{+}$ solution was diluted with methanol (at a ratio of $1 / 50$ ) in order to obtain an absorbance of $0.700 \pm 0.005$ at a wavelength of $734 \mathrm{~nm}$. A volume of $100 \mu$ l of plant extract solution prepared at different concentrations $(10,5,2,1$, 0.66 or $0.4 \mathrm{mg} \mathrm{ml}^{-1}$ ) was added to $3.9 \mathrm{ml}$ of $\mathrm{ABTS}^{-+}$solution (absorbance equal to $0.700 \pm 0.005$ ). After $10 \mathrm{~min}$ of 
reaction, the absorbance was measured by a spectrophotometer (Jenway 6315-United Kingdom) set to $734 \mathrm{~nm}$. Trolox (6-hydroxy-2,5,7,8-tetramethylchroman-2-carboxylic acid) was used as standard antioxidant at a concentration range of $0-500 \mu \mathrm{M}$. The results were expressed in $\mu \mathrm{M}$ Trolox equivalent per gram of extract $\left(\mu \mathrm{M} \mathrm{TE} \mathrm{g}{ }^{-1}\right)$.

\subsubsection{DPPH radical scavenging assay}

The antiradical activity of plant extracts was determined by the DPPH radical scavenging assay according to the method adopted by Orphanides et al. [38]. A volume of $3.9 \mathrm{ml}$ of DPPH' solution $(0.3 \mathrm{mM})$ was mixed with $100 \mu \mathrm{l}$ of plant extract prepared at different concentrations (10, $5,2,1,0.66$ or $0.4 \mathrm{mg} \mathrm{ml}^{-1}$ ) and incubated for $30 \mathrm{~min}$ at room temperature. The absorbances were then measured by a spectrophotometer (Jenway 6315-United Kingdom) set to $517 \mathrm{~nm}$. Trolox was used as a standard antioxidant at a concentration range of $0-500 \mu \mathrm{M}$. The results were expressed in $\mu \mathrm{MTE} \mathrm{g}^{-1}$.

\subsubsection{Ferric reducing ability (FRAP)}

The ability of the various extracts to reduce ferric iron $\left(\mathrm{Fe}^{+3}\right)$ to ferrous iron $\left(\mathrm{Fe}^{+2}\right)$ was determined according to the protocol described by Orphanides et al. [38]. Dilutions of plant extracts and Trolox were prepared at the same concentrations as used in the antioxidant assays above. A volume of $100 \mu \mathrm{l}$ of extract was mixed with $3.9 \mathrm{ml}$ of a freshly prepared FRAP solution [0.3 $\mathrm{M}$ acetate buffer, $\mathrm{pH}=3.6,10 \mathrm{mM}$ TPTZ (2,4,6-tri-(2-pyridyl)-s-triazine) and $20 \mathrm{mM} \mathrm{FeCl}{ }_{3} \cdot 10 \mathrm{H}_{2} \mathrm{O}$ at a ratio of 10:1:1 (v/v/v)]. The mixture was then incubated at $37^{\circ} \mathrm{C}$ for $4 \mathrm{~min}$, and the absorbance was measured at a $593 \mathrm{~nm}$. Trolox was used as a standard antioxidant at a concentration range of $0-800 \mu \mathrm{M}$. The

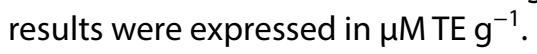

\subsubsection{Statistical analyses}

Each experiment was performed in triplicate, and the results were expressed as the mean \pm standard deviation. Variance analysis was used to test the differences between extracts and selected plant species as well as among the various techniques used to evaluate the antioxidant activity. Linear regression was used to determine the $\mathrm{IC}_{50}$ and $\mathrm{CE}_{50}$. All analyses were done by XLSTAT 2009.

\section{Results}

\subsection{Extraction yield and phytochemical analysis}

Water and methanol are the most polar solvents used in phytochemical extraction methods. Both solvents are also recommended in the literature to extract a maximum of bioactive compounds from plants $[39,40]$. According to the results presented in Table 1, the highest yields were recorded for the methanolic and aqueous extracts of $P$. lentiscus leaves, which were $22.30 \%$ and $17.44 \%$, respectively, followed in descending order by the methanolic and aqueous extracts of $A$. herba-alba and C. colocynthis seeds, which had the lowest yields with percentages of 8.14, 5.25, 3.20 and $2.26 \%$, respectively. Concerning the phytochemical screening of the studied species, Table 1 indicates all sought bioactive substances (alkaloids, flavonoids, tannins and saponosides) were detected in A. herba-alba; however, saponosides were not detected in C. colocynthis seeds, while alkaloids were not detected in P. lentiscus leaves.

\subsection{Antifungal activity}

The results confirming the purity of the selected fungal strains are shown in Fig. 3. An examination of micro-culture slides stained with lactophenol blue solution under an optical microscope clearly demonstrated that fungal strains were pure with no other microbial or fungal contamination.

In the assays measuring the antifungal effects of the plant extracts against five fungal strains, the aqueous and methanolic extracts of $A$. herba-alba were the most active (Figs. 4, 5, 6), and at concentrations greater than or equal to $50 \mathrm{mg} \mathrm{ml}^{-1}$, growth inhibition exceeded $8 \%$ (Figs. 4, 5). The most sensitive fungal strains were $P$. expansum and $A$. ochraceus followed by F. graminearum (Figs. 4, 5). According to the same figures, aqueous and methanolic extracts of the selected plant species had no effect on the growth of $A$. parasiticus and A. flavus except for the aqueous and methanolic extracts of $P$. lentiscus, which had an average
Table 1 Extraction yield and phytochemical screening

\begin{tabular}{lrrllll}
\hline & \multicolumn{2}{l}{ Extraction yield \% } & Alkaloids & Flavonoids & Tannins & Saponins \\
\cline { 2 - 5 } & Met & Aq & & & \\
\hline Plant & & & & + & + & + \\
P. lentiscus & 22.30 & 17.44 & - & + & + & + \\
A. herba-alba & 8.14 & 5.25 & + & + & + & - \\
C. colocynthis & 3.20 & 2.26 & + & + & + \\
\hline
\end{tabular}




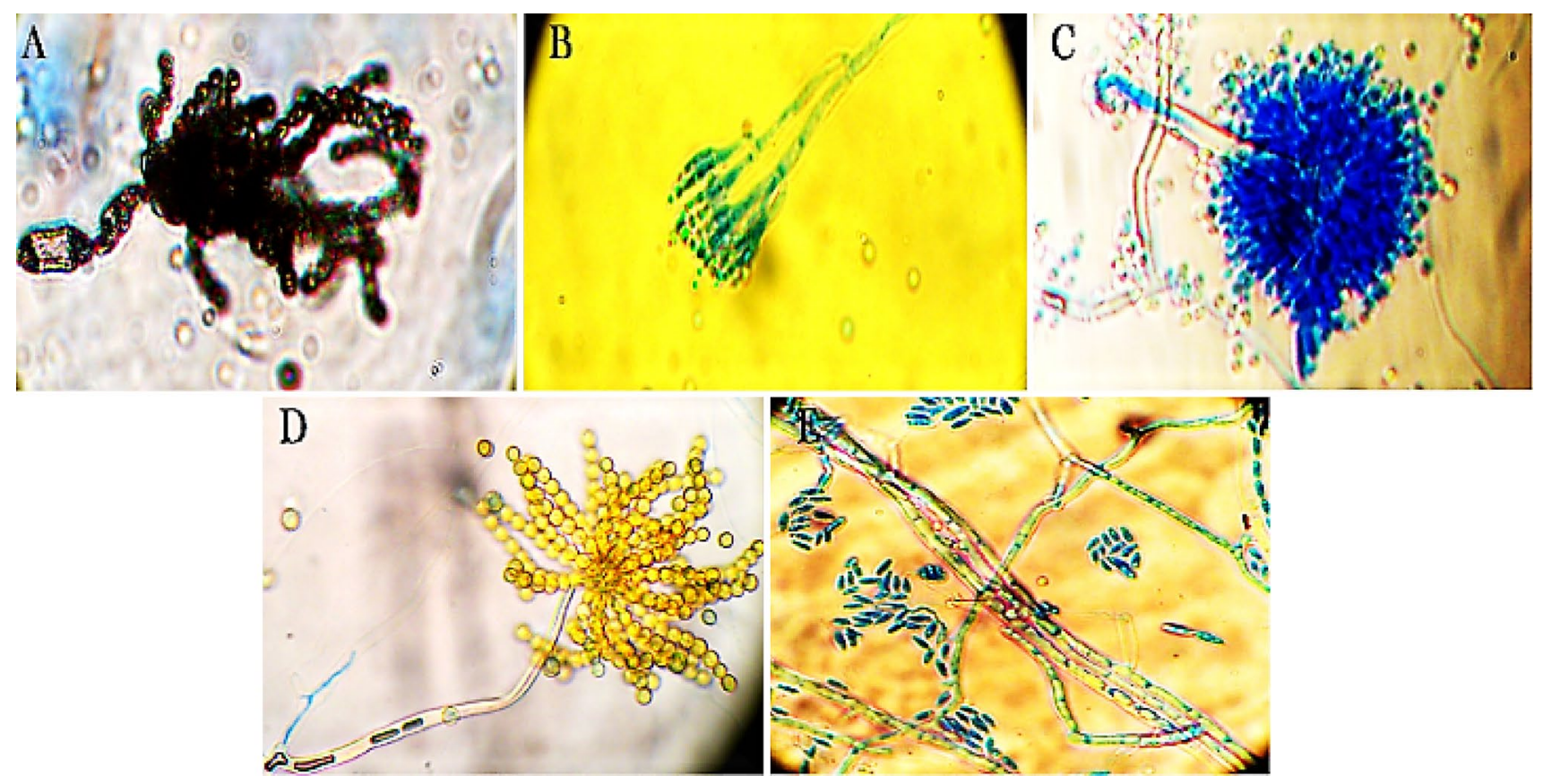

Fig. 3 Morphological appearance of fungal strains under optical microscope. a A. flavus CECT 20802, b P. expansum CECT 2278, c A. parasiticus CBS 100926, d A. ochraceus NRRL 3174, e F. graminirium CECT 2150

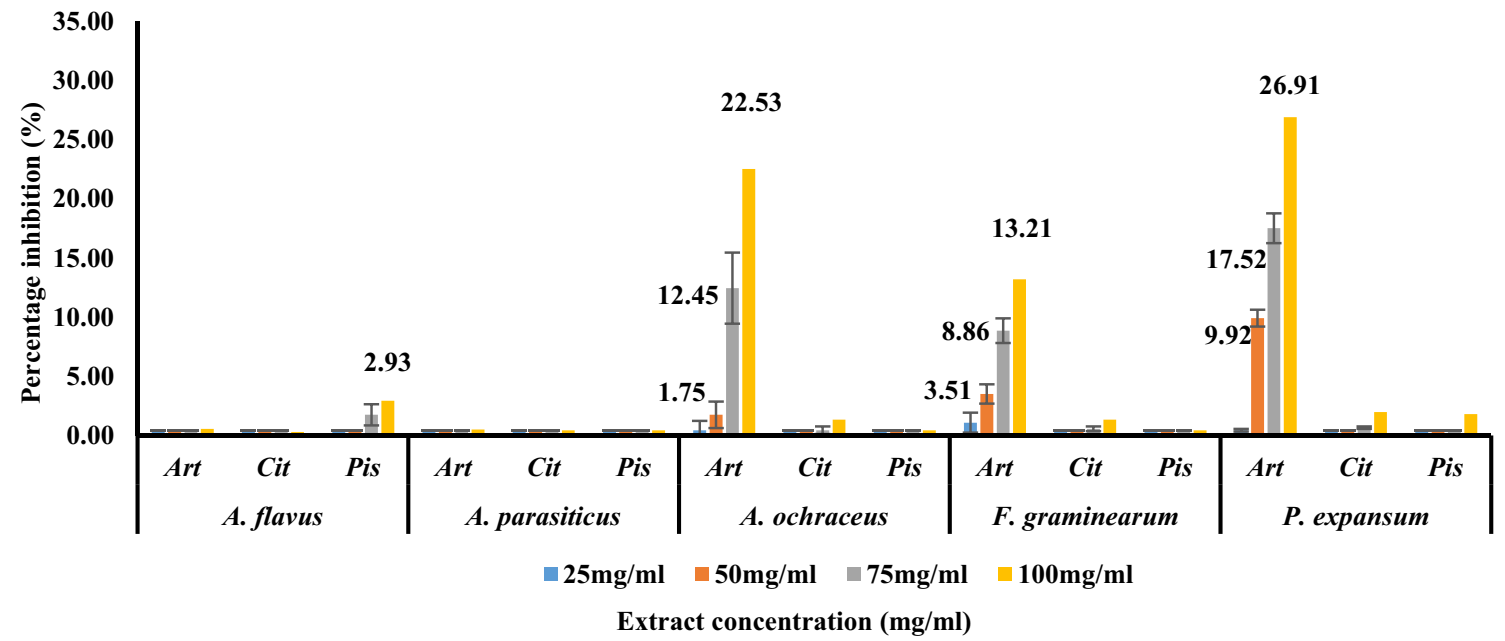

Fig. 4 Antifungal activity of aqueous extracts of the plant species. (Art: A. heba-alba, Cit: C. colocynthis and Pis: P. lentiscus)

inhibitory activity not exceeding $4 \%$ against $A$. flavus. A summary of the antifungal activity of plant extracts is shown in Table 2.

\subsection{Antioxidant activity}

The antioxidant activity of methanolic and aqueous extracts of the plants was determined in vitro by three techniques, namely, the ABTS, DPPH and FRAP assays. According to the results shown in Figs. 7, 8 and 9, the plant extracts exhibited remarkable antioxidant activity expressed in $\mu \mathrm{M} \mathrm{TE} \mathrm{g}^{-1}$. The methanolic and aqueous extracts of A. herba-alba showed the highest antioxidant activity in the FRAP assay; their reducing powers were $6080.67 \mu \mathrm{M} \mathrm{TE} \mathrm{g}^{-1}$ and $5315.11 \mu \mathrm{M} \mathrm{TE} \mathrm{g}^{-1}$, respectively. The antioxidant potentials of $P$. lentiscus leaves and $C$. colocynthis seeds measured by the same assay were lower in comparison with A. herba-alba, the values were $5300.48 \mu \mathrm{M} \mathrm{TE} \mathrm{g}^{-1}, 4123.33 \mu \mathrm{M} \mathrm{TE} \mathrm{g}^{-1}$ and

\section{SN Applied Sciences}




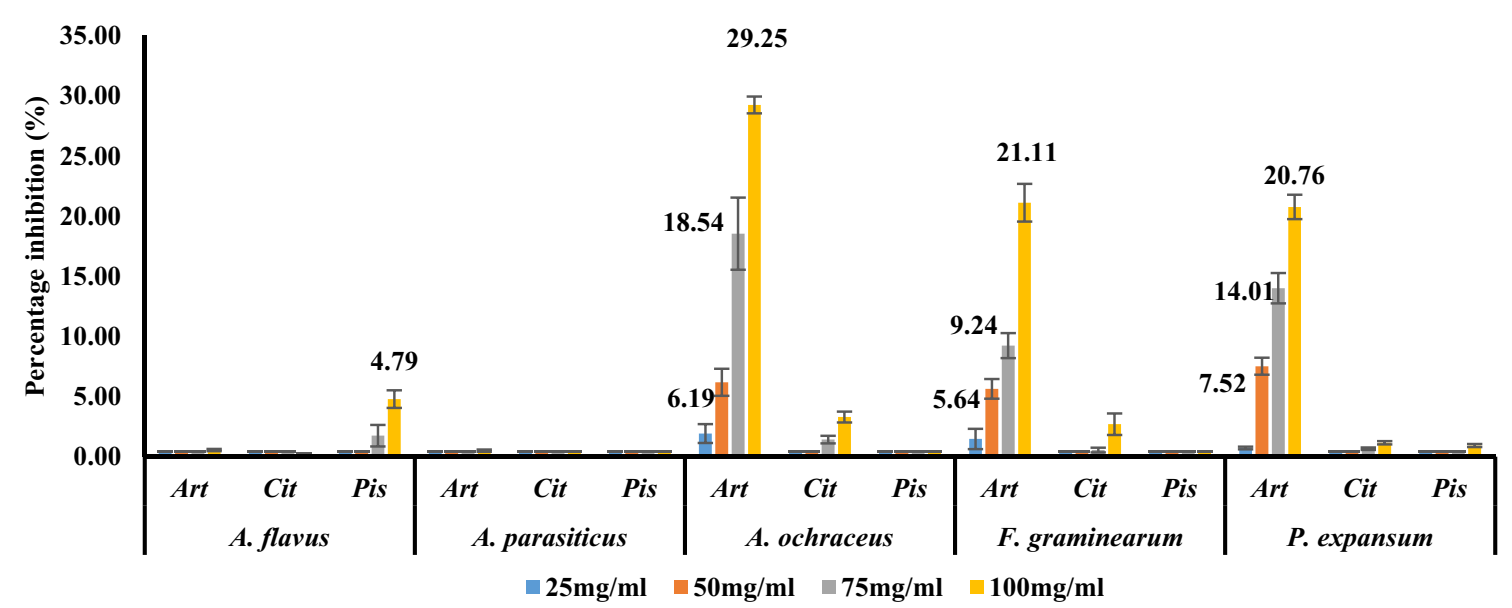

Extract concentration $(\mathrm{mg} / \mathrm{ml})$

Fig. 5 Antifungal activity of methanolic extracts of the plant species. (Art: A. heba-alba, Cit: C. colocynthis and Pis: P. lentiscus)

Fig. 6 Antifungal activity of $A$. herba-alba methanolic extract. a F. graminirium CECT 2150, b $P$. expansum CECT 2278

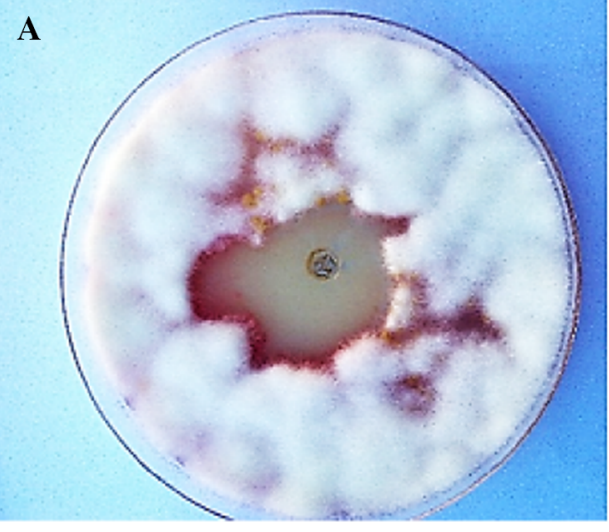

$75 \mathrm{mg} \cdot \mathrm{ml}^{-1}$

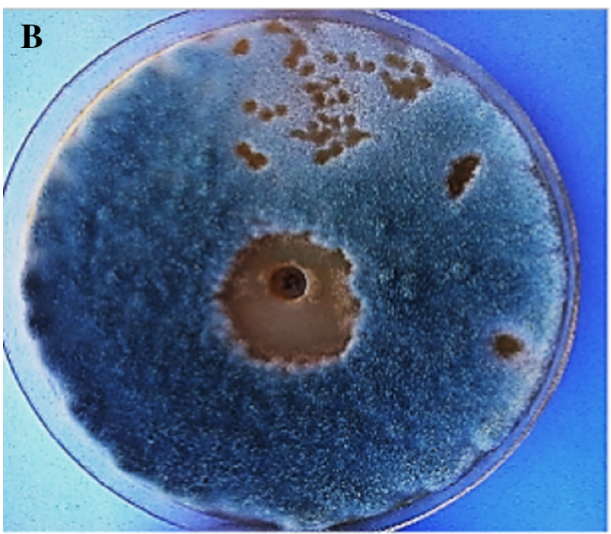

$50 \mathrm{mg} \cdot \mathrm{ml}^{-1}$

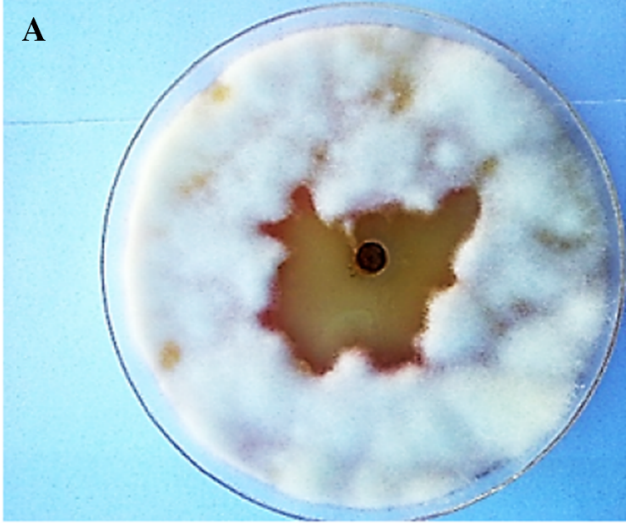

100 mg.ml ${ }^{-1}$

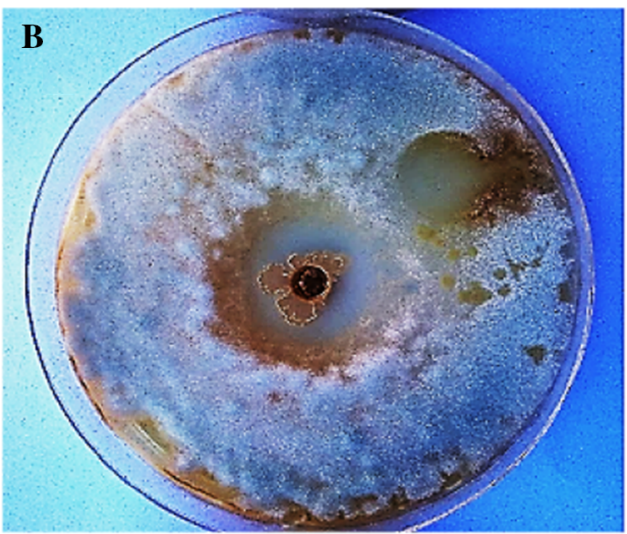

75 mg.ml ${ }^{-1}$
4150.22 $\mu \mathrm{M} \mathrm{TE} \mathrm{g}^{-1}, 3749.11 \mu \mathrm{M} \mathrm{TE} \mathrm{g}{ }^{-1}$ for the methanolic and aqueous extracts, respectively in the FRAP assay.

For all extracts, the lowest $I C_{50}$ were observed in the methanolic extracts of $A$. herba-alba in the FRAP assay, and
$\mathrm{IC}_{50}$ values was $0.91 \pm 0.92 \mathrm{mg} \mathrm{ml}^{-1}$ followed by the methanolic extracts of $P$. lentiscus leaves with $\mathrm{IC}_{50} 2.12 \pm 0.49$ measured by FRAP assay. The methanolic extracts of $C$. colocynthis seeds showed an $\mathrm{IC}_{50}$ values of $3.03 \pm 0.51$ 


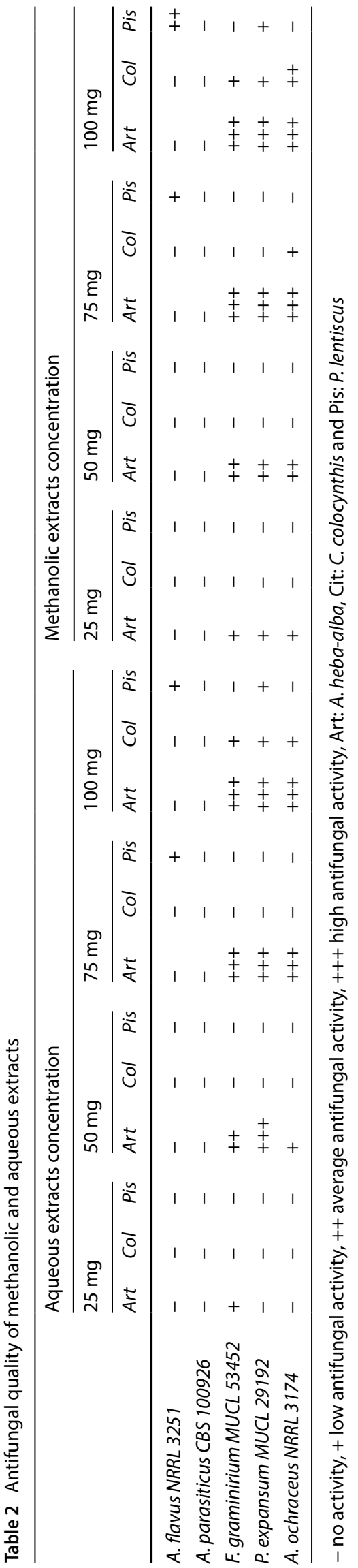

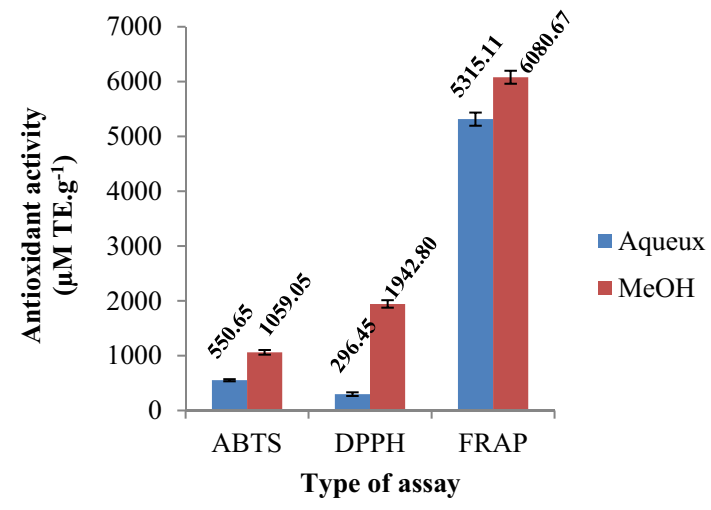

Fig. 7 Antioxidant activity of Artemisia herba-alba methanolic and aqueous extracts

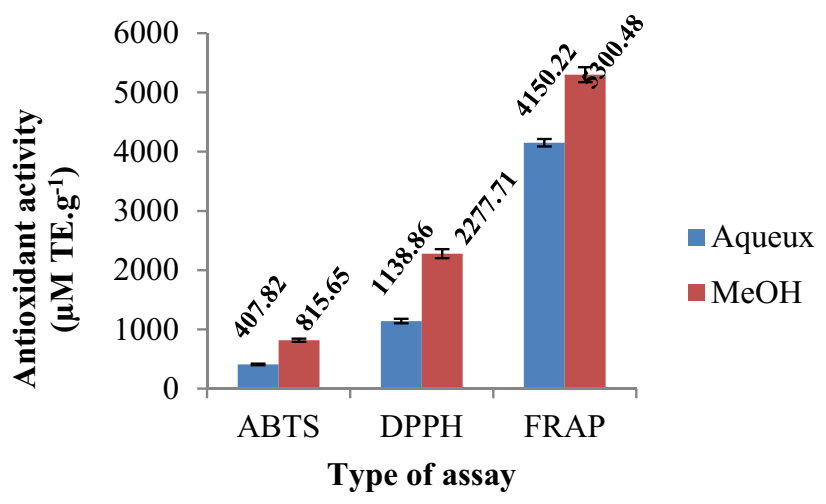

Fig. 8 Antioxidant activity of $P$. lentiscus methanolic and aqueous extracts

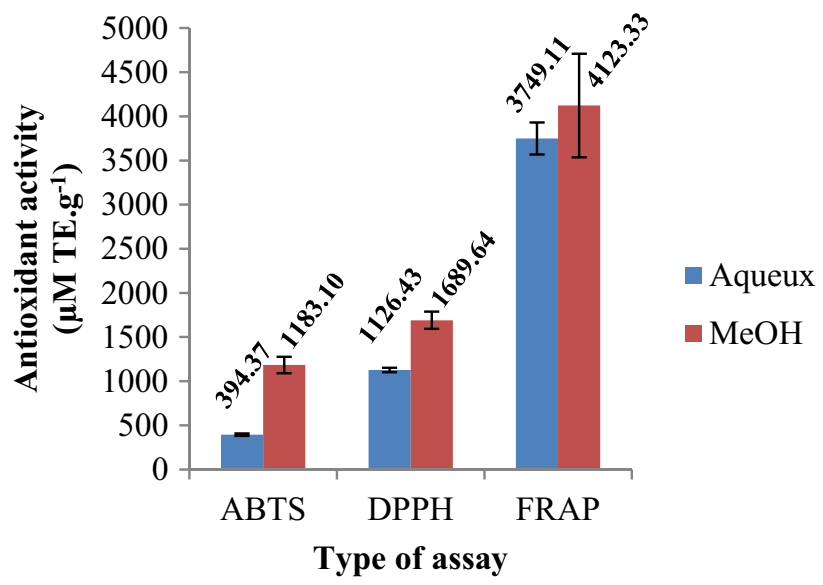

Fig. 9 Antioxidant activity of C. colocynthis methanolic and aqueous extracts

determined by the ABTS radical scavenging assay. For aqueous extracts, A. herba-alba and C. colocynthis seeds had the highest antioxidant potential with a lower $\mathrm{IC}_{50}$ 
( $2.42 \pm 0.11$ and $3.89 \pm 0.44$, respectively) followed by $P$. lentiscus leaves with $\mathrm{IC}_{50}$ values of $4.48 \pm 0.52$. However, the values of antioxidant activities evaluated by ABTS, DPPH and FRAP assays of all extracts were lower than the standard antioxidant used in this study (Trolox) (Table 3).

Variance analyses indicated that there are highly significant differences $(P<0.01)$ among the results of three antioxidant activity assays for the same species. Differences were also recorded among the three studied species $(P<0.05)$. The observed differences in the antioxidant activity among the different plant species is probably due to differences in their chemical composition. The differences among the assays seem to be due to the use of a different reaction mechanism by each assay.

\section{Discussion}

The fight against toxigenic fungi and mycotoxins is one of the difficulties of concern to scientists, and the results of extensive research in the field of mycotoxin toxicity are alarming and disturbing due to the health damage caused by mycotoxicosis and the economic losses caused by decreased food quality [41, 42]. As a result, researchers are abandoning conventional approaches and are exploring new biological control strategies against fungi and mycotoxicosis that include the use of medicinal plants [19, 20]. The three plants selected for this study were collected from semi-arid and arid regions of Algeria, which occupy more than $87 \%$ of the country's surface area. The desert regions are characterized by arid climates, in which rainfall is almost absent, with high temperatures, and in some areas of these desert regions, the climate is characterized by extreme aridity. In terms of flora, these arid and semiarid areas are habitats for more than 2800 species [43], and this biodiversity is why these sites were chosen for plant sampling.

The study of the biological activities of aromatic and medicinal plants is based on extraction, and its principle, which is the crucial stage of any study, is that welldescribed precautions must be taken into consideration in order to avoid the loss, deformation or destruction of extracted molecules; in this case, the choice of solvent and extraction conditions depends on the targeted bioactive compound and it nature [44]. Regarding yield, the study of Barbouchi and his collaborators [45] demonstrated that the infusion extraction, or Soxhlet, method gave a higher yield without neglecting the nature of the solvent or the area where the leaves were harvested. Gupta and his team obtained a lower extraction yield compared to our yield for $C$. colocynthis seeds [46].

The organic extractions of this study were carried out by maceration, and the two solvents used were of polar 
nature; consequently, the metabolites indentified were polar nature (alkaloids, flavonoids, tannins and saponins). In this context, Barbouchi's study demonstrated that organic extracts of $P$. lentiscus leaves are rich in catechic tannins, gallic tannins, flavonoids and saponins but not alkaloids [45]. Khlifi's study demonstrated that the hydromethanolic extract of $A$. herba-alba is rich in compound phenolics, flavonoids, tannins and anthocyanins [27]. Regarding the seeds of $C$. colocynth, Benariba et al. [47] revealed that catechic tannins and flavonoids are abundant in hydromethanol extracts, and according to Najafi et al. [48], the ethanolic extract contains tannins, alkaloids, flavonoids, and saponins. These differences in results may be attributed to differences in harvesting region, soil composition, climate, harvest season, solvents and experimental conditions of extraction.

In our assays, A. herba-alba exhibited the highest antifungal activity, followed in descending order by C. colocynthis seed and $P$. lentiscus leaf extracts. F. graminearum, $P$. expansum and $A$. ochraceus were the most sensitive moulds. F. graminearum is an opportunistic pathogen of cereals responsible for yield losses and contamination by its mycotoxins [49]. P. expansum, also known as blue mould, is responsible for the most important diseases of pome fruits and causes significant economic losses [50]. A. ochraceus is responsible for chronic granulomatous diseases [51]. A. flavus and A. parasiticus are known in mycology for their negative impact on health and for economic damage $[41,52]$. In this study, these two fungi were the most resistant to the various prepared extracts.

Our results are in agreement with previous studies. $P$. lentiscus is considered to be an antimicrobial plant [53, 54], and ethanolic extracts of its fruits and leaves are used as ingredients in pork sausage to reduce microbial spoilage [55]. Some studies found that organic extracts of $C$. colocynthis are more active in comparison to aqueous extracts [47] and that hydromethanolic extracts are less toxic against $F$. oxysporum and its enzymes (CMCase, pectinase, and protease) [56] and exhibit a moderate antifungal activity against $A$. fumigatus DSM790 and $A$. niger DSM1988 [57].

The antifungal activities of the extracts are largely attributed to the solvent extraction capacity and the concentration of the active compounds in the crude extracts [58]. The sensitivity of microorganisms is due to the intolerance of cells to phytochemicals and their interactions with fungal cell components, which can cause, for example, the inhibition of cell wall formation, rupture of the cell membrane, mitochondria dysfunction, inhibition of cell division, inhibition of DNA replication, inhibition of protein synthesis or inhibition of efflux pumps [59]. However, the resistance of fungal strains may be due to degradation of bioactive compounds by fungal enzymes, removal of bioactive substances by efflux systems, insensitivity of the site targeted by the molecule [60] or by mutations in the genes encoding fungicide targets [61]. Tannins due to their structure interact with ergosterol and damage cell membranes [62]. Flavonoids and alkaloids are also known for their antimicrobial and spasmolytic activities $[63,64]$.

The complexity and multifunctionality of phytochemicals make the use of a single test insufficient to evaluate the antioxidant activity $[65,66]$. The antioxidant activity assays carried out in this study made it possible to measure the capacities of the various bioactive molecules present in the crude extracts to donate an electron to a radical or to an ion, which leads to the inhibition or reduction of oxidants. The plant extracts prepared in this study showed good antioxidant potential in the three assays, and the ability of these extracts to reduce free radicals can be attributed to their phenolic and flavonoid compounds $[67,68]$, whose chemical structures and concentrations determine the antioxidant activity [69].

The results of the antioxidant activity assays in this study are consistent with those of a recent study done on A. herba-alba from another region [70], and another study supports our results and demonstrates that this plant reduces the oxidative damage induced by alloxan [71]. Khlifi et al. [27] reported that the hydromethanolic extract had $\mathrm{IC}_{50}$ values of $20.64 \pm 0.84 \mathrm{mg} \mathrm{ml}^{-1}$ and $36.60 \pm 1.03 \mathrm{mg} \mathrm{ml}^{-1}$ in the DPPH and ABTS assays, respectively.

Several other studies support our results and state that $P$. lentiscus has good antioxidant activity revealed by the DPPH and ABTS assays [72-75]. Barbouchi et al. [45] reported that the antioxidant activity of $P$. lentiscus leaves varies according to the location of harvest and observed $\mathrm{IC}_{50}$ values ranging from $0.50 \pm 0.00$ to $0.09 \pm 0.00 \mathrm{mg} \mathrm{ml}^{-1}$ and from $0.57 \pm 0.00$ to $1.13 \pm 0.00 \mathrm{mg} \mathrm{ml}^{-1}$ for the aqueous and methanolic extracts, respectively. Botsaris et al. [55] demonstrated that the methanolic extracts prevent lipid oxidation. Some authors showed that this activity is strongly due to the presence of gallic acid, 1,2,3,4,6-pentagalloyl glucose, 5-O-galloyl, 3,5-di-O-galloyl and 3,4,5-triO-galloyl and observed an $\mathrm{IC}_{50}$ equal to $3.9 \mu \mathrm{M}[76,77]$.

For $C$. colocynthis, several in vivo and in vitro studies reported good antioxidant activity in the fruits $[47,78]$. Marzouk et al. [79] stated that the $\mathrm{IC}_{50}$ of aqueous seed extracts is between 0.020 and $0.021 \mathrm{mg} \mathrm{ml}^{-1}$ and attributed this difference to the different stages of fruit ripening. In contrast, Jayaraman and Christina [80] found that the maximum inhibition of DPPH radicals by the methanolic extract was approximately $62 \%$ at $0.8 \mathrm{mg} \mathrm{ml}^{-1}$, whereas we observed only $57.11 \%$ of DPPH radical scavenging at $10 \mathrm{mg} \mathrm{ml}^{-1}$ methanolic extract. Tannin-Spitz et al. [81] reported that cucurbitacin B glucoside and cucurbitacin 
E glucoside widely detected in C. colocynthis are powerful antioxidants.

\section{Conclusion}

Ethnopharmacological surveys based on scientific approaches and research oriented towards the exploitation of medicinal plants have been growing steadily in recent years due to pharmaceutical and medical interest in the bioactive substances isolated from these plants and characterized by less lethal side effects. These preliminary studies are of great importance in the development of plant-based pharmaceuticals and in the progression of green nanotechnology leading to the synthesis of new complex nanoparticles doped with bioactive substances active against multiresistant fungal strains. The results of the current study confirm that Artemisia herba-alba, Pistacia lentiscus and Citrullus colocynthis are potential sources of bioactive substances that could be used in the control of food contamination and of oxidative stress and the prevention of mycotoxicoses. Additional studies are in progress to characterize the structure of bioactive compounds and to elucidate their antifungal mechanisms in vitro by molecular docking.

Acknowledgements We are thankful to the researchers from the Laboratory of Ecosystems Protection in Arid and Semi-Arid Area, University of Kasdi Merbah-Ouargla, Algeria for their support during this work.

\section{Compliance with ethical standards}

Conflict of interest The authors declare that they have no conflict of interest.

\section{References}

1. Milićević DR, Skrinjar M, Baltić T (2010) Real and perceived risks for mycotoxin contamination in foods and feeds: challenges for food safety control. Toxins 2(4):572-592

2. Hou YJ, Zhao YY, Xiong B, Cui XS, Kim NH, Xu YX, Sun SC (2013) Mycotoxin-containing diet causes oxidative stress in the mouse. PLoS ONE 8(3):e60374

3. Limonciel A, Jennings $P$ (2014) A review of the evidence that ochratoxin A is an Nrf2 inhibitor: implications for nephrotoxicity and renal carcinogenicity. Toxins 6(1):371-379

4. Theumer MG, Henneb Y, Khoury L, Snini SP, Tadrist S, Canlet C, Puel O, Oswald IP, Audebert M (2018) Genotoxicity of aflatoxins and their precursors in human cells. Toxicol Lett 287:100-107

5. Mehrzad J, Malvandi AM, Alipour M, Hosseinkhani S (2017) Environmentally relevant level of aflatoxin B1 elicits toxic proinflammatory response in murine CNS-derived cells. Toxicol Lett 279:96-106

6. Gayathri L, Karthikeyan BS, Rajalakshmi M, Dhanasekaran D, Li AP, Akbarsha MA (2018) Metabolism-dependent cytotoxicity of citrinin and ochratoxin A alone and in combination as assessed adopting integrated discrete multiple organ coculture (IdMOC). Toxicol In Vitro 46:166-177

7. Al-Anati L, Petzinger E (2006) Immunotoxic activity of ochratoxin A. J Vet Pharmacol Ther 29(2):79-90

8. Loiseau N, Debrauwer L, Sambou T, Bouhet S, Miller JD, Martin PG, Viadère JL, Pinton P, Puel $O$, Pineau T, Tulliez J, Galtier P, Oswald IP (2007) Fumonisin B1 exposure and its selective effect on porcine jejunal segment: sphingolipids, glycolipids and trans-epithelial passage disturbance. Biochem Pharmacol 74(1):144-152

9. Constable PD, Smith GW, Rottinghaus GE, Haschek WM (2000) Ingestion of fumonisin B1-containing culture material decreases cardiac contractility and mechanical efficiency in swine. Toxicol Appl Pharmacol 162(3):151-160

10. Magnussen A, Parsi MA (2013) Aflatoxins, hepatocellular carcinoma and public health. World J Gastroenterol 19(10):1508-1512

11. Varga J, Kocsubé S, Péteri Z, Vágvölgyi C, Tóth B (2010) Chemical, physical and biological approaches to prevent ochratoxin induced toxicoses in humans and animals. Toxins 2(7):1718-1750

12. Calado T, Fernández-Cruz ML, Cabo Verde $S$, Venâncio $A$, Abrunhosa $L$ (2018) Gamma irradiation effects on ochratoxin A: degradation, cytotoxicity and application in food. Food Chem 240:463-471

13. Štikarová J, Kotlín R, Riedel T, Suttnar J, Pimková K, Chrastinová L, Dyr JE (2013) The effect of reagents mimicking oxidative stress on fibrinogen function. Sci World J 2013:359621

14. Fatokun AA, Stone TW, Smith RA (2006) Hydrogen peroxideinduced oxidative stress in MC3T3-E1 cells: the effects of glutamate and protection by purines. Bone 39(3):542-551

15. Chang Q, Wang W, Regev-Yochay G, Lipsitch M, Hanage WP (2015) Antibiotics in agriculture and the risk to human health: how worried should we be? Evol Appl 8(3):240-247

16. Kohanski MA, Dwyer DJ, Wierzbowski J, Cottarel G, Collins JJ (2008) Mistranslation of membrane proteins and two-component system activation trigger antibiotic-mediated cell death. Cell 135(4):679-690

17. Dwyer DJ, Belenky PA, Yang JH, MacDonald IC, Martell JD, Takahashi N, Chan CT, Lobritz MA, Braff D, Schwarz EG, Ye JD, Pati M, Vercruysse M, Ralifo PS, Allison KR, Khalil AS, Ting AY, Walker GC, Collins JJ (2014) Antibiotics induce redox-related physiological alterations as part of their lethality. Proc Natl Acad Sci USA 111(20):E2100-E2109

18. Fink-Gremmels $J(2008)$ The impact of mycotoxins in animal feeds. In: Leslie JF, Bandyopadhyay R, Visconti A (eds) Mycotoxins. Detection methods, management, public health and agricultural trade. CABI, Wallingford, pp 163-165

19. Owumi SE, Oloidi AC, Oloye CO, Oladeji OO, Obadare MO, Odunola OA (2015) Toxicological and phytoprotective effect of Keayodendron bridelioides and Monodora myristica extracts in Wister rats. Pharmacognosy Res 7(Suppl 1):S26-S33

20. Njoki LM, Okoth SA (2017) Wachira PM (2017) Effects of medicinal plant extracts and photosensitization on aflatoxin producing Aspergillus flavus (Raper and Fennell). Int J Microbiol 5:1-9

21. Reddy KRN, Muralidharan K, Reddy CS (2009) Potential of botanicals and biocontrol agents on growth and aflatoxin production by Aspergillus flavus infecting rice grains. Food Control 20(2):173-178

22. Elsherbiny EA, El-Khateeb AY, Azzaz NA (2016) Chemical composition and fungicidal effects of Ocimum basilicum essential oil on Bipolaris and Cochliobolus species. J Agric Sci Technol 18(4):1143-1152

23. Barghamdi B, Ghorat F, Asadollahi K, Sayehmiri K, Peyghambari R, Abangah G (2016) Therapeutic effects of Citrullus colocynthis 
fruit in patients with type II diabetes: a clinical trial study. J Pharm Bioallied Sci 8(2):130-134

24. Gowri SS, Priyavardhini S, Vasantha K, Umadevi M (2009) Antibacterial activity on Citrullus colocynthis Leaf extract. Anc Sci Life 29(1):12-13

25. Chowdhury K, Sharma A, Kumar S, Gunjan GK, Nag A, Mandal CC (2017) Colocynth extracts prevent epithelial to mesenchymal transition and stemness of breast cancer cells. Front Pharmacol 8:593

26. Moufid A, Eddouks M (2012) Artemisia herba alba: a popular plant with potential medicinal properties. Pak J Biol Sci 15(24):1152-1159

27. Khlifi D, Sghaier RM, Amouri S, Laouini D, Hamdi M, Bouajila $J$ (2013) Composition and anti-oxidant, anti-cancer and antiinflammatory activities of Artemisia herba-alba, Ruta chalpensis L. and Peganum harmala L. Food Chem Toxicol 55:202-208

28. Zeggwagh NA, Michel JB, Eddouks M (2014) Acute hypotensive and diuretic activities of Artemisia herba- alba aqueous extract in normal rats. Asian Pac J Trop Biomed 4(2):S644-S648

29. Bozorgi M, Memariani Z, Mobli M, Salehi Surmaghi MH, ShamsArdekani MR, Rahimi R (2013) Five Pistacia species ( $P$. vera, $P$. atlantica, $P$. terebinthus, $P$. khinjuk, and $P$. lentiscus): a review of their traditional uses, phytochemistry, and pharmacology. Sci World J 2013:219815

30. Telli A, Esnault MA, Khelil OEH (2016) An ethnopharmacological survey of plants used in traditional diabetes treatment in southeastern Algeria (Ouargla province). J Arid Environ 127:82-92

31. Jasso de Rodriguez D, Hernández-Castillo D, Rodriguez-Garcia $\mathrm{R}$, Angulo-Sánchez JL (2005) Antifungal activity in vitro of Aloe vera pulp and liquid fraction against plant pathogenic fungi. Ind Crops Prod 21(1):81-87

32. Senhaji O, Faid M, Elyachioui M, Dehhaoui M (2005) Antifungal activity of different cinnamon extracts. J Med Mycol 15(4):220-229

33. Al-Daihan S, Al-Faham M, Al-shawi N, Almayman R, Brnawi A, Zargar S, Bhat RS (2013) Antibacterial activity and phytochemical screening of some medicinal plants commonly used in Saudi Arabia against selected pathogenic microorganisms. J King Saud Univ 25(2):115-120

34. Aylmore RC, Todd NK (1984) A microculture chamber and improved method for combined light and electron microscopy of filamentous fungi. J Microbiol Methods 2(6):317-322

35. Magnusson J, Schnürer J (2001) Lactobacillus coryniformis subsp. coryniformis strain si3 produces a broad-spectrum proteinaceous antifungal compound. Appl Environ Microbiol 67(1):1-5

36. Espinel-Ingroff A, Cantón E (2007) Antifungal susceptibility testing of filamentous fungi. In: Schwalbe R, Steele-Moore L, Goodwin AC (eds) Antimicrobial susceptibility testing protocols, 1st edn. CRC Press, Boca Raton, pp 209-241

37. Surveswaran S, Cai YZ, Corke H, Sun M (2007) Systemic evaluation of natural phenolic antioxidants from 133 Indian medicinal plants. Food Chem 102(3):938-953

38. Orphanides A, Goulas V, Gekas V (2013) Effect of drying method on the phenolic content and antioxidant capacity of spearmint. Czech J Food Sci 31(5):509-513

39. Liharaka Kidaha M, Alakonya AE, Nyende AB (2013) Bioactivity determination of methanol and water extracts for roots and leaves of Kenyan Psidium guajava $L$ landraces against pathogenic bacteria. Springerplus 2:670

40. Seo J, Lee S, Elam ML, Johnson SA, Kang J, Arjmandi BH (2014) Study to find the best extraction solvent for use with guava leaves (Psidium guajava L.) for high antioxidant efficacy. Food Sci Nutr 2(2):174-180

41. Gacem MA, Ould El Hadj-Khelil A (2016) Toxicology, biosynthesis, bio-control of aflatoxin and new methods of detection. Asian Pac J Trop Biomed 6(9):808-814
42. Mitchell NJ, Bowers E, Hurburgh C, Wu F (2016) Potential economic losses to the US corn industry from aflatoxin contamination. Food Addit Contam Part A Chem Anal Control Expo Risk Assess 33(3):540-550

43. Halla N, Boucherit K, Boucherit Otmani Z, Touati FZ, Rahmani N, Aid I (2018) Ammodaucus leucotrichus and Citrullus colocynthis from Algerian Sahara: Ethnopharmacological application, phytochemical screening, polyphenols content and antioxidant activity of hydromethanolic extracts. J King Saud Univ Sci. https://doi.org/10.1016/j.jksus.2018.03.018

44. Sasidharan S, Chen Y, Saravanan D, Sundram KM, Yoga Latha L (2011) Extraction, isolation and characterization of bioactive compounds from plants' extracts. Afr J Tradit Complement Altern Med 8(1):1-10

45. Barbouchi M, Elamrani K, El Idrissi M, Choukrad M (2018) A comparative study on phytochemical screening, quantification of phenolic contents and antioxidant properties of different solvent extracts from various parts of Pistacia lentiscus L. J King Saud Univ Sci. https://doi.org/10.1016/j.jksus .2018.05.010

46. Gupta SC, Tripathi T, Paswan SK, Agarwal AG, Rao CV, Sidhu OP (2018) Phytochemical investigation, antioxidant and wound healing activities of Citrullus colocynthis (bitter apple). Asian Pac J Trop Biomed 8(8):418-424

47. Benariba N, Djaziri R, Bellakhdar W, Belkacem N, Kadiata M, Malaisse WJ, Sener A (2013) Phytochemical screening and free radical scavenging activity of Citrullus colocynthis seeds extracts. Asian Pac J Trop Biomed 3(1):35-40

48. Najafi S, Sanadgol N, Sadeghi NB, Ashofteh BM, Sanadgol E (2010) Phytochemical screening and antibacterial activity of Citrullus colocynthis (Linn.) Schrad against Staphylococcus aureus. J Med Plants Res 4(22):2321-2325

49. Boedi S, Berger H, Sieber C, Münsterkötter M, Maloku I, Warth B, Sulyok M, Lemmens M, Schuhmacher R, Güldener U, Strauss $J$ (2016) Comparison of Fusarium graminearum transcriptomes on living or dead wheat differentiates substrate-responsive and defense-responsive genes. Front Microbiol 7:1113

50. Sánchez-Torres $P$, Vilanova $L$, Ballester AR, López-Pérez $M$, Teixidó N, Viñas I, Usall J, González-Candelas L, Torres R (2018) Unravelling the contribution of the Penicillium expansum PeSte12 transcription factor to virulence during apple fruit infection. Food Microbiol 69:123-135

51. Moazam S, Denning DW (2017) Aspergillus nodules in chronic granulomatous disease attributable to Aspergillus ochraceus. Med Mycol Case Rep 17:31-33

52. Sánchez E, Heredia N, García S (2005) Inhibition of growth and mycotoxin production of Aspergillus flavus and Aspergillus parasiticus by extracts of Agave species. Int J Food Microbiol 98(3):271-279

53. Mezni F, Aouadhi C, Khouja ML, Khaldi A, Maaroufi A (2015) In vitro antimicrobial activity of Pistacia lentiscus L. edible oil and phenolic extract. Nat Prod Res 29(6):565-570

54. Bonifácio BV, dos Santos Ramos MA, da Silva PB, Bauab TM (2014) Antimicrobial activity of natural products against Helicobacter pylori: a review. Ann Clin Microbiol Antimicrob 13:54

55. Botsaris G, Orphanides A, Yiannakou E, Gekas V, Goulas V (2015) Antioxidant and antimicrobial effects of Pistacia lentiscus L. extracts in pork sausages. Food Technol Biotechnol 53(4):472-478

56. Mohamed MSM, Saleh AM, Abdel-Farid IB, El-Naggar SA (2017) Growth, hydrolases and ultrastructure of Fusarium oxysporum as affected by phenolic rich extracts from several xerophytic plants. Pestic Biochem Physiol 141:57-64

57. Eidi S, Azadi HG, Rahbar N, Mehmannavaz HR (2015) Evaluation of antifungal activity of hydroalcoholic extracts of Citrullus colocynthis fruit. J Herb Med 5(1):36-40 
58. Iloki-Assanga SB, Lewis-Luján LM, Lara-Espinoza CL, Gil-Salido AA, Fernandez-Angulo D, Rubio-Pino JL, Haines DD (2018) Solvent effects on phytochemical constituent profiles and antioxidant activities, using four different extraction formulations for analysis of Bucida buceras L. and Phoradendron californicum. BMC Res Notes 8:396

59. Lagrouh F, Dakka N, Bakri Y (2017) The antifungal activity of Moroccan plants and the mechanism of action of secondary metabolites from plants. J Med Myc 27(3):303-311

60. Morrissey JP, Osbourn AE (1999) Fungal resistance to plant antibiotics as a mechanism of pathogenesis. Microbiol Mol Biol Rev 63(3):708-724

61. Deising HB, Reimann S, Pascholati SF (2008) Mechanisms and significance of fungicide resistance. Braz J Microbiol 39(2):286-295

62. Lopes G, Pinto E, Andrade PB, Valentão P (2013) Antifungal activity of phlorotannins against dermatophytes and yeasts: approaches to the mechanism of action and influence on Candida albicans virulence factor. PLoS ONE 8(8):e72203

63. Panche AN, Diwan AD, Chandra SR (2017) Flavonoids: an overview. J Nutr Sci 5:e47

64. Khan H, Mubarak MS, Amin S (2017) Antifungal potential of alkaloids as an emerging therapeutic target. Curr Drug Targets 18(16):1825-1835

65. Škrovánková S, Mišurcová L, Machů L (2012) Antioxidant activity and protecting health effects of common medicinal plants. Adv Food Nutr Res 67:75-139

66. Ortega-Ramirez LA, Rodriguez-Garcia I, Leyva JM, Cruz-Valenzuela MR, Silva-Espinoza BA, Gonzalez-Aguilar GA, Siddiqui W, Ayala-Zavala JF (2014) Potential of medicinal plants as antimicrobial and antioxidant agents in food industry: a hypothesis. $J$ Food Sci 79(2):R129-R137

67. Pourreza N (2013) Phenolic compounds as potential antioxidant. Jundishapur J Nat Pharm Prod 8(4):149-150

68. Huyut Z, Beydemir Ş, Gülçin I (2017) Antioxidant and antiradical properties of selected flavonoids and phenolic compounds. Biochem Res Int 2017:1-10

69. Do QD, Angkawijaya AE, Tran-Nguyen PL, Huynh LH, Soetaredjo FE, Ismadji S, Ju YH (2014) Effect of extraction solvent on total phenol content, total flavonoid content, and antioxidant activity of Limnophila aromatica. J Food Drug Anal 22(3):296-302

70. Dif MM, Benali Toumi F, Boukaaza H, Mokaddem F, Benyahia M, Bouazza S (2018) Phenolic content and antioxidant activity of Artemisa herba-alba, A medicinal plant from Algerian arid zone. Phytothérapie 16(2):91-95

71. Sekiou O, Boumendjel M, Taibi F, Boumendjel A, Messarah M (2018) Mitigating effects of antioxidant properties of Artemisia herba alba aqueous extract on hyperlipidemia and oxidative damage in alloxan-induced diabetic rats. Arch Physiol Biochem 125(2):163-173
72. Papada E, Forbes A, Amerikanou C, Torović L, Kalogeropoulos N, Tzavara C, Triantafillidis JK, Kaliora AC (2018) Antioxidative efficacy of a Pistacia Lentiscus supplement and its effect on the plasma amino acid profile in inflammatory bowel disease: a randomised, double-blind, placebo-controlled trial. Nutrients 10(11):pii: 1779

73. Yemmen $M$, Landolsi A, Ben Hamida J, Mégraud F, Trabelsi Ayadi M (2017) Antioxidant activities, anticancer activity and polyphenolics profile, of leaf, fruit and stem extracts of Pistacia lentiscus from Tunisia. Cell Mol Biol (Noisy-le-grand) 63(9):87-95

74. Belhachat D, Aid F, Mekimene L, Belhachat M (2017) Phytochemical screening and in vitro antioxidant activity of Pistacia lentiscus berries ethanolic extract growing in Algeria. Med J Nutr Metab 10(2):273-285

75. Beghlal D, El Bairi K, Marmouzi I, Haddar L, Mohamed B (2016) Phytochemical, organoleptic and ferric reducing properties of essential oil and ethanolic extract from Pistacia lentiscus (L.). Asian Pac J Trop Dis 6(4):305-310

76. Abdelwahed A, Bouhlel I, Skandrani I, Valenti K, Kadri M, Guiraud P, Steiman R, Mariotte AM, Ghedira K, Laporte F, Dijoux-Franca MG, Chekir-Ghedira L (2007) Study of antimutagenic and antioxidant activities of gallic acid and 1,2,3,4,6-pentagalloylglucose from Pistacia lentiscus. Confirmation by microarray expression profiling. Chem Biol Interact 165(1):1-13

77. Baratto MC, Tattini M, Galardi C, Pinelli P, Romani A, Visioli F, Basosi R, Pogni R (2003) Antioxidant activity of galloyl quinic derivatives isolated from $P$. lentiscus leaves. Free Radic Res 37(4):405-412

78. Vakiloddin S, Fuloria N, Fuloria S, Dhanaraj SA, Balaji K, Karupiah $S$ (2015) Evidences of hepatoprotective and antioxidant effect of Citrullus colocynthis fruits in paracetamol induced hepatotoxicity. Pak J Pharm Sci 28(3):951-957

79. Marzouk Z, Marzouk B, Mahjoub MA, Haloui E, Mighri Z, Aouni M, Fenina $N$ (2010) Screening of the antioxidant and the free radical scavenging potential of Tunisian Citrullus colocynthis Schrad. from Mednine. J Food Agric Environ 8(2):261-265

80. Jayaraman R, Christina AJM (2013) Evaluation of Citrullus colocynthis fruits on in vitro antioxidant activity and in vivo DEN/PB induced hepatotoxicity. Int J Appl Res Nat Prod 6(1):1-9

81. Tannin-Spitz T, Bergman M, Grossman S (2007) Cucurbitacin glucosides: antioxidant and free-radical scavenging activities. Biochem Biophys Res Commun 364(1):181-186

Publisher's Note Springer Nature remains neutral with regard to jurisdictional claims in published maps and institutional affiliations. 